\title{
КЛИНИЧЕСКИЙ СЛУЧАЙ ВЕДЕНИЯ БЕРЕМЕННОСТИ У ПАЦИЕНТКИ С GCK/MODY2
}

\author{
'Плеханова М.А., 'Бурумкулова Ф.Ф., '²убкова Н.А., 'Панов А.Е.', 'Петрухин В.А., ${ }^{2}$ Тюльпаков А.Н. \\ 'ГБУз МО Московский областной НИИ акушерства и гинекологии, Москва \\ ${ }^{2}$ ФБГУ «НМИЦ эндокринологии» Минздрава России, Москва
}

ЦЕЛЬ: изучить особенности течения беременности с впервые выявленной гипергликемией, обусловленной мутацией в гене глюкокиназы.

МАТЕРИАЛЫ И МЕТОДЫ: беременной с впервые выявленной гипергликемией проведено молекулярно-генетическое исследование (МГИ) с помощью метода высокоэффективного параллельного секвенирования. Поиск аналогичных мутаций у ребенка проводился методом прямого секвенирования Сэнгера, лаборатория отделения наследственных эндокринопатий ФГБУ «НМИЦ эндокринологии» МЗ РФ (зав. отд., д.м.н. Тюльпаков А.Н.). Оценивалась гликемии по триместрам, данные представлены как медиана (нижний квартиль; верхний квартиль), \% гипергликемий ( $\geq 7,0$ ммоль/л через час после еды), \% гипогликемий (<3,9 ммоль/л). Гликемия фиксировалась в электронном приложении. Работа проведена при поддержке гранта РНФ № 16-15-10408.

РЕЗУЛЬТАТЫ: пациентка 34 года с ИМТ 19,61 кг/м² обратилась в клинику на сроке 8 недель 1-й беременности. Наследственность по нарушениям углеводного обмена отягощена в трех поколениях. Ранее гипергликемия не зафиксирована. Глюкоза венозной плазмы (ГВП) натощак - 7,5 ммоль/л, постпрандиальная гликемия 12-14 ммоль/л, $\mathrm{HbA}_{1 c}-5,6 \%$, аутоантитела (GAD, ICA, IA-2) - отрицательные. Инициирована инсулинотерапия в базис-болюсном режиме. Потребность в инсулине в 1-м триместре - 0,3 ед/кг/сут, гликемия - 6,5 [5,9;7,5] с колебаниями от 3,9 до 12,9 ммоль/л, из них гипогликемий - 0\%, гипергликемий- 32,8\%. Несмотря на высокую комплаентность беременной, гликемия во II триместре не достигала целевых значений - M 6,0 [5,0;7,1], колебания 1,1 - 13,8 ммоль/л, гипогликемий - 10,7\%, гипергликемий - 27,4\%. В 3-м триместре доза инсулина составляла - 0,7 ед/кг/сут, гликемия М 6,4 [5,3;7,6], при этом гликемия в диапазоне от 3 до 14,3 ммоль/л, из них 6\% - гипогликемии, 35,3\% - гипергликемии. Несмотря на высокий процент нецелевой гликемии по данным УзИ отмечалось снижение окружности живота с 84 до 16 П (с 16,3 по 34,6 неделю). Частота гипогликемий соответствовала аналогичный частоте, наблюдаемой во время беременности у пациентов с СД1, что значительно выше, чем при ГСД, при котором гипогликемия наблюдается редко. За весь период беременности было выполнено 1027 измерений гликемии. На сроке 39 недель родился доношенный живой мальчик, вес 3170 г (45,39 П), рост 52 см $(94,73$ П). МГИ выявило ранее не описанную гетерозиготную мутацию p.G246E в гене GCK у матери и новорожденного.

Выводы: беременность у пациентов с мутациями в гене GCK манифестирует ранней, гипергликемией, часто в диабетическом диапазоне на фоне отрицательных аутоантител. Течение беременности характеризуется высокой вариабельность гликемии и низкой чувствительностью к экзогенному инсулину. Данный клинический случай иллюстрирует отсутствие влияния материнской гипергликемии, на весо-ростовые показатели плода при рождении, если он унаследовал аналогичную мутацию. 